\title{
A survey of trainees' perspectives on epidural training in the United Kingdom
}

\author{
R. Isaacs ${ }^{1}$, MYK. Wee $^{2}$, VN Dubey ${ }^{3}$ and N. Vaughan ${ }^{4}$ \\ ${ }^{1}$ Department of Anaesthesia, University Hospital Southampton, Southampton, Hampshire, UK \\ ${ }^{2}$ Department of Anaesthesia, Poole Hospital NHS Foundation Trust, Poole, Dorset, UK \\ ${ }^{3}$ Associate Professor of Research, Bournemouth University, Faculty of Science and Technology, Poole House, Talbot Campus, Poole, Dorset, UK \\ ${ }^{4}$ Post-doctorate Researcher, Bournemouth University, Faculty of Science and Technology, Poole House, Talbot Campus, Poole, Dorset, UK
}

\begin{abstract}
Background: Establishment of epidural analgesia is one of the most difficult technical skills in which to become proficient. We explored the current United Kingdom system of training in epidural insertion amongst trainee members of the Obstetric Anaesthetists' Association (OAA).

Methods: An electronic questionnaire was sent to 452 OAA trainee members in May 2012. Questions were based upon own personal experience, challenges currently faced and the use of epidural simulation to enhance training.

Results: Although the majority felt ready and prepared when initially performing epidurals solo, $66 \%$ found the experience very stressful and $25 \%$ felt under considerable time pressure. Although senior support was readily available, $36 \%$ felt uncertain much of the time and $9 \%$ were unsure when to call for help. The European Working Time Directive was felt to have impacted upon training by $54 \%$ of respondents. $40 \%$ believe that there exists more challenging patients who require more experienced operators. Although 53\% had used an epidural simulator previously, $84 \%$ would recommend its use for trainees and $49 \%$ would support simulator use as a compulsory element of training.

Conclusions: In spite of changes to the medical profession, there appears to be a robust system of training for epidural analgesia. However, there still exists the need to reduce the impact of the learning curve upon workplace stress for trainees. Whether this involves increased direct supervision for more than just the bare minimum, structured feedback tools to enhance the supervisor/trainee experience or the use of high-fidelity epidural simulation remains to be seen.
\end{abstract}

\section{Introduction}

The Royal College of Anaesthetists' National Audit Project 3 showed that from approximately 700,000 central neuraxial blocks performed annually in the UK, $40 \%$ are epidurals (Cook, Counsell and Wildsmith, 2009) [1]. Incidence of permanent harm from all epidurals ranged from 3.1 to 6.1 in 100,000 . Two large studies of obstetric epidural complications report that, although rare, life-threatening complications do occur (Paech, Godkin, Webster, 1998; Jenkins, 2005) $[2,3]$. Post-dural puncture headache $(\mathrm{PDPH})$ has a more frequent occurrence of approximately $1 \%$ (Gleeson and Reynolds, 1998) [4]. Yet Gupta, Collis and Harries (2007) identified an increasing dural tap rate of $2.8 \%$ at their tertiary level unit when data over the preceding five years was analysed [5]. Ascribing this to decreasing trainee experience, they highlight the need to "focus on new methods of training in epidural insertion," with a warning in case this was perhaps part of a national trend rather than just a local occurrence.

Cumulative sum (cusum) analysis is a statistical and graphical tool that examines trends for sequential events over time and can be used to determine proficiency in technical procedures. Naik, Devito and Halpem (2003) found that novices attain epidural insertion competency between 1 and 85 attempts, with many requiring almost 75 attempts [6]. Konrad et al. (1998) demonstrated success rates of $80 \%$ after 90 attempts [7]. Such numbers may be difficult to achieve within defined training periods. Recent reviews have commented on poorly structured systems for teaching skill acquisition and highlight the shift away from practicing on patients due to reduced tolerance for medical error (Grantcharov, Reznick, 2008; Smith, Johannsson, Sadler, 2005; Aggarwal and Darzi, 2006) [8-10]. Watterson et al. (2007) surveyed 29 Australian junior anaesthetists attempting to learn epidural insertion [11]. Teaching was described as "guided practical experience on patients provided by a senior registrar or consultant" but most felt stressed and described "low levels of control over some aspects of their workplace, including preparation before practice, access to supervision and volume of experience." Watterson suggested augmenting training through enhanced supervision, structured feedback tools and simulation

The current obesity epidemic poses greater challenges for the novice anaesthetist. Bamgbade et al. (2009) found that obese labouring women were significantly more likely to need three or more attempts to achieve successful regional anaesthesia [12]. Perlow and Morgan (1994) demonstrated that in obese parturients more than one attempt

Correspondence to: Richard Isaacs, Department of Anaesthesia, University Hospital Southampton, Tremona Rd, Southampton. SO16 6YD, UK; E-mail: risaacs@doctors.org.uk

Key words: complications, epidural analgesia, epidural simulation, training, workplace stress

Received: August 10, 2015; Accepted: September 08, 2015; Published: September 11, 2015 
at epidural insertion was necessary in $75 \%$ and more than three attempts in $14 \%$ [13].

To explore the UK training structure for learning the epidural technique, we sent a questionnaire to all trainee members of the Obstetric Anaesthetists' Association (OAA). The aim was to identify experience in epidural training, potential challenges and difficulties and the place of epidural simulation for training in the obstetric setting.

\section{Methods}

After approval from the audit sub-committee of the OAA, an electronic questionnaire was sent to all 452 trainee members in May 2012, followed by two reminder e-mails to non-responders. All responses were anonymous. Trainee members were targeted since this group is likely to comprise of anaesthetists who are currently involved in both spectrums of the epidural training programme; either those still progressing along the learning curve or those who can clearly remember their own training but are more involved with the supervised training of others.

\section{Results}

In total, 207 of 452 questionnaires were completed, giving a response rate of $46 \%$. Approximately $80 \%$ were senior trainees (final three years of training) and $15 \%$ were junior trainees. The remaining responses came from those who had taken up fellowship roles. Of respondents, 91\% had performed over 100 epidurals.

\section{Training experience and outcomes}

The first epidural ever attempted by the trainee was a non-obstetric lumbar epidural (58\%), labour epidural (33\%) and thoracic epidural (9\%). Over $80 \%$ felt prepared, understood the anatomy and knew the risks before independent practice. Ninety percent felt able to summon senior assistance if required. However, $66 \%$ found the experience very stressful. Thirty-six percent felt a degree of uncertainty, with $9 \%$ unsure when to summon help. Twenty-five percent felt time-pressured by midwives/theatre practitioners (Table 1). Reported complications associated with individual trainees' first 20-25 epidural insertions included a dural puncture in $37 \%(\mathrm{n}=76)$, short-term neuropathy in $3 \%(\mathrm{n}=7)$ and a 'high block' defined as bradycardia, respiratory dysfunction or loss of consciousness in $4 \%(n=8)$. There were no cases of permanent neuropathy.

\section{Learning environment}

Fifty-four percent believed the European Working Time Directive had negatively influenced training. Minimally invasive surgery and regional blocks have not had a major impact on epidural training with agreement responses of 50\% and $21 \%$ respectively. Few (19\%) believe that the number of trainees or increased emphasis on patient safety is an issue, but $40 \%$ felt that there are more challenging patients who require experienced epiduralists (Table 2).

\section{Supervision}

As expected from the seniority of respondents, $90 \%$ have been involved in the supervision of junior trainees trying to learn the epidural technique. Table 3 outlines various statements regarding how the trainee felt about supervising a more junior colleague. There were 185 responses in total, reflecting the fact that not all have been involved in a supervisory capacity.

\section{Epidural simulation}

There was an approximately equal divide between those that had used a simulator for training themselves/teaching others and those that had never used one (53\% vs. $47 \%$ ). However, $84 \%$ (176/206) would recommend simulator use for novices and this number included those that had not used one previously. Opinions were divided regarding simulation as a compulsory element with $49 \%$ stating that trainees must demonstrate competency on a simulator prior to patient interaction. Table 4 outlines some of the features deemed crucial to a good epidural simulator.

\section{Discussion}

This survey reveals a high degree of satisfaction amongst trainees at all stages. The majority felt able to call for senior assistance, believed senior staff were supportive and were encouraged to ask for help. In the authors' region, trainees undertake a minimum of ten supervised epidurals prior to independent practice. There is no specific guidance, except to attain basic level competencies in obstetric anaesthesia one must safely conduct epidural analgesia using specific assessment methods to identify competence. Regional or perhaps hospital variation may exist and it would be useful to know what the set standard is and how many epidurals the respondents initially sited under direct supervision. Workplace stress amongst anaesthetists is frequently reported (Larsson, Rosenqvist, Holmstrom, 2006; Jackson, 1999; Houston, Allt, 1999) [1416]. The survey findings are significant and may translate into the need for more direct supervision or a comprehensive training program, including the use of simulation. Negotiating learning support to match supervisory assistance to trainees' needs has been recognised as being an important part of the process. Trainees possess insight into the level of support they require, be it direct senior presence, feedback or a consultant scrubbed and ready to step-in, but few are explicit in their requirements.

Complication rate analysis does not enable accurate assessments

Table 1. Survey responses of 207 trainees regarding a range of measures to determine training effectiveness.

\begin{tabular}{|c|c|c|}
\hline Measure & Statement & Agreement $^{*}$ \\
\hline \multirow[t]{3}{*}{ Satisfaction with training } & I was observed and given feedback on enough cases to feel confident to perform the procedure solo & $82 \%$ \\
\hline & I had a thorough understanding of spinal anatomy & $81 \%$ \\
\hline & I had a good understanding of the risks and complications involved & $91 \%$ \\
\hline \multirow[t]{2}{*}{ Self-assessment of help-seeking } & I knew how to troubleshoot when I was having difficulty & $51 \%$ \\
\hline & I could easily call for help if I was struggling to site the epidural & $90 \%$ \\
\hline \multirow[t]{4}{*}{ Workplace stress } & Performing epidurals was very stressful & $66 \%$ \\
\hline & I felt uncertain a lot of the time & $36 \%$ \\
\hline & I felt uncertain about when I should call for assistance & $9 \%$ \\
\hline & I felt under considerable time pressures from midwives/ODPs & $25 \%$ \\
\hline
\end{tabular}

"Percentage of trainees agreeing or strongly agreeing with each statement. 
Table 2. Survey responses of 207 trainees regarding a range of factors that may impact upon epidural training.

\begin{tabular}{|l|c|}
\hline \multicolumn{1}{|c|}{ Influence } & Agreement $^{*}$ \\
\hline European Working Time Directive (EWTD) & $54 \%$ \\
\hline Minimally invasive surgery & $50 \%$ \\
\hline More challenging patients requiring more experienced operators & $40 \%$ \\
\hline Reduced obstetric on-call requirement & $22 \%$ \\
\hline Increased use of rectus sheath/TAP blocks/remifentanil PCA in labour & $21 \%$ \\
\hline Increased emphasis on patient safety & $19 \%$ \\
\hline Too many trainees around trying to site epidurals & $19 \%$ \\
\hline
\end{tabular}

"Percentage of trainees agreeing or strongly agreeing with each statement.

Table 3. Survey responses of 185 trainees regarding supervision of more junior colleagues.

\begin{tabular}{|l|c|}
\hline Statement & Agreement $^{*}$ \\
\hline $\begin{array}{l}\text { Sometimes I'm sure the patient doesn't quite know who } \\
\text { exactly is putting in the epidural }\end{array}$ & $47 \%$ \\
\hline I'd prefer the consultant to supervise novices & $25 \%$ \\
\hline $\begin{array}{l}\text { I usually let the novice have one quick go then step in if } \\
\text { there are any problems }\end{array}$ & $23 \%$ \\
\hline $\begin{array}{l}\text { I'd be happy to supervise a junior even though they may } \\
\text { not be so familiar with the equipment or anatomy }\end{array}$ & $22 \%$ \\
\hline
\end{tabular}

"Percentage of trainees agreeing or strongly agreeing with each statement.

Table 4. Survey responses of 207 trainees regarding the importance of various features that could be incorporated into the design of a new epidural simulator in descending order.

\begin{tabular}{|l|c|}
\hline \multicolumn{1}{|c|}{ Simulator feature } & Agreement $^{*}$ \\
\hline Ability to palpate anatomical landmarks & $96 \%$ \\
\hline Realistic loss of resistance & $93 \%$ \\
\hline Ability to adjust patient position & $83 \%$ \\
\hline Accommodates patient habitus (elderly, obese, pregnancy) & $79 \%$ \\
\hline Ability to provide feedback on competency & $75 \%$ \\
\hline Loss of resistance to saline and air & $74 \%$ \\
\hline Physical appearance of the manikin & $55 \%$ \\
\hline Ultrasound compatibility & $52 \%$ \\
\hline Recreation of environmental factors (movement, noise) & $45 \%$ \\
\hline
\end{tabular}

"Percentage of trainees agreeing or strongly agreeing with each statement

of epidural teaching adequacy. However, inadvertent dural puncture may be considered separately since it is more likely to occur during the steep learning phase. This may be from poor understanding of the technique or inadequate teaching. Of the respondents, $37 \%$ ( $\mathrm{n}=$ 76) had experienced a dural tap during their first 25 insertions. To note, multiple dural taps from each trainee were not accounted for and novices were under-represented. Tan et al. (2010) described an inadvertent dural puncture rate of $1.4 \%$ due to medical officers rotating to the delivery suite every six months [17]. Through a structured epidural training program, the incidence fell to $0.3 \% 1$ and $0.8 \%$ over subsequent six-month periods. Perhaps it is now incumbent upon trainers to attempt to reduce this complication rate by determining the ideal training programme.

It is encouraging, if not surprising, that most would recommend simulator use, even when they had not used one previously. Perhaps because of limited design and utility, only two-thirds of those who had previously encountered manikin-simulation found it useful and less believed that it should be compulsory. Cost-efficiency savings have an impact on what can be purchased and epidural simulators may be low on the list, especially when 'better' models come at higher prices. But we have a duty of care to our patients and our trainees to make the procedure as safe and stress-free as possible.

The two fundamental issues with regards the learning environment is patient safety and trainee welfare. This survey confirms the need to lessen the impact of the initial learning curve to reduce trainee anxiety. Whether this involves increased direct supervision, structured feedback tools or epidural simulation remains to be seen.

Surveying OAA trainee members was based upon the fact that this cohort includes trainees who can recall their learning experience and may supervise junior colleagues. Although there is the potential for bias from the low number of novice trainees represented in our survey and the fact that those surveyed do have a particular interest in obstetric anaesthesia, the results still reveal interesting features derived from 207 trainees in the UK. The lack of questioning of non-OAA members and the possibility of positive recall bias is thus a limitation.

\section{Conclusions}

This survey has confirmed the robustness of the current training system in spite of the various changes to medical practice which is reassuring but there still exists the need to lessen the impact of the initial learning curve to reduce trainee anxiety. The results of this survey suggest we do need to focus our attention more on this aspect. Whether this involves increased direct supervision, structured feedback tools to enhance the supervisor/trainee experience or the use of improved epidural simulation remains to be seen. For the latter though, it is clear that to serve its purpose, an epidural simulator must be of high technical fidelity at an affordable price. The need for awareness about stress in anaesthesia and a consideration of other strategies to combat it is also vitally important.

\section{Acknowledgements}

We wish to acknowledge the support of Obstetric Anaesthetists' Association for reviewing the survey questions and for providing access to their survey software system.

\section{References}

1. Cook TM, Counsell D, Wildsmith JA; Royal College of Anaesthetists Third National Audit Project (2009) Major complications of central neuraxial block: report on the Third National Audit Project of the Royal College of Anaesthetists. Br J Anaesth 102: 179-190. [Crossref]

2. Paech MJ, Godkin R, Webster S (1998) Complications of obstetric epidural analgesia and anaesthesia: a prospective analysis of 10,995 cases. Int J Obstet Anesth 7: 5-11. [Crossref]

3. Jenkins JG (2005) Some immediate serious complications of obstetric epidura analgesia and anaesthesia: a prospective study of 145,550 epidurals. Int J Obstet Anesth 14: 37-42. [Crossref]

4. Gleeson CM, Reynolds F (1998) Accidental dural puncture rates in UK obstetric practice. Int J Obstet Anesth 7: 242-246. [Crossref]

5. Gupta S, Collis R, Harries S (2007) Increasing dural tap rate: is this a national trend? Int J Obstet Anesth 16: S17.

6. Naik VN, Devito I, Halpern SH (2003) Cusum analysis is a useful tool to assess resident proficiency at insertion of labour epidurals. Can J Anaesth 50: 694-698. [Crossref]

7. Konrad C, Schüpfer G, Wietlisbach M, Gerber H (1998) Learning manual skills in anesthesiology: Is there a recommended number of cases for anesthetic procedures? Anesth Analg 86: 635-639. [Crossref]

8. Grantcharov TP, Reznick RK (2008) Teaching procedural skills. BMJ 336: 1129-1131 [Crossref]

9. Smith TS, Johannsson HE, Sadler C (2005) Trials of labour: can simulation make a difference to obstetric anaesthetic training? Curr Anaes Crit Care 16: 289-296. 
10. Aggarwal R, Darzi A (2006) Technical-skills training in the 21st century. N Engl J Med 355: 2695-2696. [Crossref]

11. Watterson LM, Hyde S, Bajenov S, Kennedy SE (2007) The training environment of junior anaesthetic registrars learning epidural labour analgesia in Australian teaching hospitals. Anaesth Intensive Care 35: 38-46. [Crossref]

12. Bamgbade OA, Khalaf WM, Ajai O, Sharma R, Chidambaram V, et al. (2009) Obstetric anaesthesia outcome in obese and non-obese parturients undergoing caesarean delivery: an observational study. Int J Obstet Anesth 18: 221-225. [Crossref]

13. Perlow JH, Morgan MA (1994) Massive maternal obesity and perioperative cesarean morbidity. Am J Obstet Gynecol 170: 560-565. [Crossref]
14. Larsson J, Rosenqvist U, Holmström I (2006) Being a young and inexperienced trainee anesthetist: a phenomenological study on tough working conditions. Acta Anaesthesiol Scand 50: 653-658. [Crossref]

15. Jackson SH (1999) The role of stress in anaesthetists' health and well-being. Acta Anaesthesiol Scand 43: 583-602. [Crossref]

16. Houston DM, Allt SK (1999) Junior house officers one year on: changes in psychological distress and error making. Psychol Health Med 4: 281-287.

17. Tan CH, Ithnin F, Leong SB (2010) A Structured Epidural Training Program Decreased the Incidence of Inadvertent Dural Puncture in Patients Requesting for Labour Analgesia. ANZCA Annual Scientific Meeting, Christchurch, New Zealand.

Copyright: @2015 Isaacs R. This is an open-access article distributed under the terms of the Creative Commons Attribution License, which permits unrestricted use, distribution, and reproduction in any medium, provided the original author and source are credited. 